\section{ECOFRIENDLY ELECTRONIC CIGARETTES}

Ecofriendly electronic cigarettes Nicolites contain no tobacco, tar, carbon monoxide or other harmful substances and can be smoked in all public places with no ash or cigarette ends but real smoking satisfaction. There is no tobacco smoke - instead a water vapour is exhaled that you can even blow smoke rings with.

The odourless Nicolites taste, feel and look like the real thing.

Nicolites are reliable and consistent and come ready to use. No charging is necessary and one lasts up to 25 traditional cigarettes' worth before needing to be disposed of.

Traditional electronic cigarettes are made up of a battery, an atomiser and a nicotine containing cartridge. With Nicolites the atomiser has been combined with the cartridge. Simply screw the two pieces together and Nicolites are ready to use. Reader response number 50

\section{KIDS ENCOURAGED TO UPCYCLE}

Aquafresh manufacturers GSK have teamed up with upcycling company TerraCycle UK to launch the Aquafresh oral care Brigade, a recycling fundraiser which encourages schools to collect used toothbrushes and toothpaste tubes to be recycled and upcycled into everyday products.

For every product brought in for recycling, $2 \mathrm{p}$ will be donated to a charity of the school's choice. The scheme teaches children about resource conservation whilst reinforcing good dental hygiene through educational materials on brushing for kids.

The scheme works well with the interactive oral care education programme 'Brushing Buddies' launched by the Aquafresh team last year, designed for children aged 3-6.

For more

information visit:

www.terracycle.co.uk. Reader response number 51

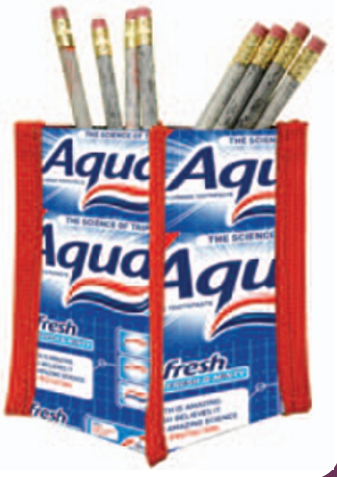

\section{LESS INTENSE AND ALCOHOL FREE}

Johnson \& Johnson now offer a less intense, alcohol-free version of Listerine Mouthwash - Listerine Zero.

The new product is alcohol-free for a less intense taste, but still contains the classic Listerine four essential oils: menthol, thymol, methyl salicylate and eucalyptol. Listerine Zero kills up to $99 \%$ of plaque bacteria in vitro, more than other alcohol-free, daily use mouthwashes. Listerine Zero also contains 220 ppm (0.05\%) fluoride for effective enamel protection.

Listerine Zero has been developed to address the individual needs of patients who may, for lifestyle, health or religious reasons, or on grounds of taste, prefer a less intense, alcohol-free mouthwash. In consumer tests, over $70 \%$ of participants liked the milder taste of Listerine Zero.

For dental professionals, there is now a less intense and alcohol-free, yet highly effective daily use mouthwash within the Listerine range to suit the individual needs of some patients and to help them achieve a cleaner, fresher and healthier mouth beyond toothbrushing and interdental cleaning alone.

Reader response number 52

\section{WHOLE TOOTH PROTECTION}

GSK has launched Aquafresh Ultimate - a new premium toothpaste that delivers whole

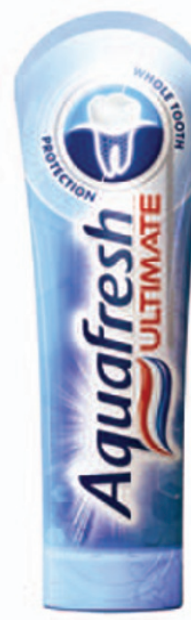
tooth protection by strengthening the tooth above the gum line, whilst its unique formulation kills bacteria to help keep the gum seal tight and healthy, protecting what's vulnerable below the gum line.

With its range of product benefits and a great taste, Aquafresh Ultimate will appeal to the whole family, especially to parents who believe that it is important to have healthy teeth and are willing to invest time and money to achieve this.

Aquafresh Ultimate comes in a stand-up carton-less tube with shelfready trays for maximum stand out. The cartons feature a stunning tooth graphic using Fresnel lens technology to provide holographic images on flat surfaces. Combined with the familiar Aquafresh logo and three-striped icon, it creates a fresh new look whilst retaining the brand's core values.

Two mint flavoured $75 \mathrm{ml}$ varieties - Aquafresh Ultimate and Aquafresh Ultimate Whitening - are available now.

Reader response number 53

\section{REPAIR \& PROTECT AT SHOWCASE}

Visitors to the BDTA Dental Showcase 2011 in Birmingham can find out more about new Sensodyne Repair \& Protect by visiting stand $\mathrm{C} 10$. This new daily fluoride toothpaste contains advanced NovaMin technology which delivers clinically

proven relief from dentine hypersensitivity with twice daily brushing.

Details of the science behind the active ingredient of the product will be available on the stand including images of the substantive reparative layer which is built up by NovaMin overexposed dentine, using the natural building blocks of teeth.

The GSK team will be on hand throughout the exhibition to provide information on their full portfolio of oral care brands including Aquafresh, Biotène, Corsodyl, Poligrip, Pronamel and Sensodyne.

Reader response number 54 